\title{
Transgenic Calmodulin-Dependent Protein Kinase II Activation: Dose-Dependent Effects on Synaptic Plasticity, Learning, and Memory
}

\author{
Rafael Bejar, ${ }^{1}$ Rie Yasuda, ${ }^{2,4}$ Harmen Krugers, ${ }^{3}$ Kristin Hood, ${ }^{1}$ and Mark Mayford ${ }^{1,4}$ \\ ${ }^{1}$ Neurosciences Graduate Program, University of California at San Diego, La Jolla, California 92093, ${ }^{2}$ Genomics Institute \\ of the Novartis Research Foundation, San Diego, California 92121, ${ }^{3}$ Swammerdam Institute for Life Sciences, Section of \\ Neurobiology, University of Amsterdam, 1090GB The Netherlands, and ${ }^{4}$ Department of Cell Biology, The Scripps \\ Research Institute, La Jolla, California 92037
}

Genetic disruption of calmodulin-dependent protein kinase II (CaMKII) function alters hippocampal synaptic plasticity and memory in mice. We used transgenic mice carrying a tetracycline-regulated, calcium-independent form of CaMKII (CaMKII-Asp286) to investigate the role of CaMKII activation on synaptic plasticity and behavior. Mice expressing low levels of a CaMKII-Asp286 transgene have facilitated low-frequency (5 $\mathrm{Hz}$ )-induced long-term potentiation (LTP), whereas mice with high levels of transgene expression have a deficit in this form of plasticity. Behavioral impairments on fear-conditioned memory and visible water maze correlate with the level of CaMKII-
Asp286 expression. Mice with high levels of CaMKII-Asp286 have reversible, compensatory changes in the expression of genes associated with inhibitory neurotransmission. These results demonstrate that in the hippocampus, CaMKII activation facilitates the induction of low-frequency LTP, but at high levels of expression, compensatory mechanisms act to inhibit the induction of this form of LTP. The most severe behavioral impairments are associated with activation of this compensatory mechanism.

Key words: memory; CaMKII; mice; transgenic; tetracycline; genetic compensation; long-term potentiation
In the CA1 region of the hippocampus, both biochemical and pharmacological studies demonstrate that activation of calmodulin-dependent protein kinase II (CaMKII) is required for the establishment of long-term potentiation (LTP) (Malenka et al., 1989; Malinow et al., 1989; Lisman et al., 1997). Deletion of the $\mathrm{CaMKII} \alpha$ gene results in mice with deficient hippocampal LTP and spatial-memory impairments (Silva et al., 1992a,b). CaMKII is thought to act through autophosphorylation at a critical threonine residue ( $\mathrm{Thr} 286)$ that converts the kinase to a calcium-independent state. Indeed, mutation of $\mathrm{CaMKII} \alpha-$ Thr286 to alanine to prevent this autophosphorylation impairs LTP and spatial memory (Giese et al., 1998). Moreover, introduction of an activated calcium-independent form of CaMKII into CA1 neurons potentiates synaptic transmission and occludes LTP (Pettit et al., 1994; Lledo et al., 1995; Hayashi et al., 2000). These results are consistent with the view that CaMKII underlies at least one form of hippocampal LTP and that this LTP may, in turn, be required for the establishment of spatial memories.

Complementary studies in transgenic mice expressing a constitutively active calcium-independent mutant form of CaMKII failed to support the view that CaMKII activation alone is sufficient to produce LTP (Bach et al., 1995; Mayford et al., 1995, 1996). In the mutant mice, high-frequency LTP in the Schaffer collateral pathway was unaffected by the transgene. Instead, these mice were deficient in LTP induced by $5-10 \mathrm{~Hz}$ stimulation such

\footnotetext{
Received Jan. 21, 2002; revised April 12, 2002; accepted April 12, 2002.

This work was supported by grants from the National Institutes of Health (M.M., R.B.), the McKnight Foundation (M.M.), and the Klingenstein Foundation (M.M.). Correspondence should be addressed to Mark Mayford, Cell Biology, ICND202, The Scripps Research Institute, La Jolla, CA 92037. E-mail: mmayford@ scripps.edu.

Copyright (C) 2002 Society for Neuroscience $\quad 0270-6474 / 02 / 225719-08 \$ 15.00 / 0$
}

that a shift toward long-term depression (LTD) was observed in response to stimulation in this frequency range. These results argued that the level of CaMKII activity in the neuron controls a form of metaplasticity that determines the size and direction of synaptic change caused by specific patterns of activity.

Although genetically modified mice are a powerful tool for the specific molecular manipulation of a whole-animal model, there are two difficulties in interpreting results of such experiments in terms of the function of the gene under study (Mayford and Kandel, 1999). The first is that when the genetic change is present for the entire developmental history of the animal, it is possible that the phenotypes observed in the adult are the result of genetically induced developmental abnormalities. The second difficulty is that the alteration of a single gene may induce compensatory changes in other downstream genes. We have attempted to address the issues of gene dosage, developmental abnormalities, and genetic compensation in transgenic mice expressing a constitutively active form of CaMKII. We find that although expression of the transgene does not produce any persistent developmental abnormalities, there is a strong effect of gene dosage. At low levels of transgene expression, $5 \mathrm{~Hz}$ LTP is actually enhanced, whereas learning and memory are modestly impaired. At high levels of transgene expression, behavioral performance and $5 \mathrm{~Hz}$ LTP are impaired, and there is a compensatory change in the expression of a number of genes associated with inhibitory neurotransmission. The implications of these results for CaMKII function and the study of mutant mice in general are discussed.

\section{MATERIALS AND METHODS}

CaMKII-Asp286 transgenic mice. Transgenic mice carrying a $\mathrm{Ca}^{2+}$ independent CaMKII transgene (CaMKII-Asp286) under the control 
of the tetracycline transactivator (tTA) were generated as described previously (Mayford et al., 1996). These mice carry two independent transgenes. The first is a CaMKII $\alpha$-Asp286 cDNA cloned downstream of the tetO promoter. The second transgene consists of the tTA gene placed downstream of the CaMKII $\alpha$ promoter. For the generation of double-transgenic animals for behavioral experiments, we bred doubletransgenic male mice carrying both the tTA- and tetO-linked transgenes to $\mathrm{C} 57 \mathrm{BL} / 6$ females and analyzed the resulting double transgenics and a control group of littermates lacking either of the two transgenes. TetOlinked transgene expression is controlled using mouse chow containing $40 \mathrm{mg} / \mathrm{kg}$ doxycycline (Dox) (Bio-serve, Frenchtown, NJ). All mice had been inbred onto a C57BL/6 background for more than five generations.

Northern blots. Immediately after killing, the mouse brain was removed and immersed in ice-cold PBS. The appropriate brain region was dissected, and total RNA was isolated using Trizol reagent (Sigma, St. Louis, MO) as recommended by the manufacturer. RNA was separated by electrophoresis on a formaldehyde-containing agarose gel, blotted to a nylon membrane, and hybridized at $55^{\circ} \mathrm{C}$ overnight with PerferctHyb (Sigma) containing $10^{6} \mathrm{cpm}$ of a radiolabeled DNA probe per milliliter of hybridization solution. The labeled blot was washed with $0.2 \times$ SSC and $0.1 \%$ SDS, and the hybridization signal was quantified using a phosphorimager.

Reverse transcription-PCR detection of CaMKII-D286 transgene $m R N A$. Reverse transcription (RT) was performed with the PerkinElmer Life Sciences (Emeryville, CA) rtTH I polymerase RNA PCR kit according to the manufacturer's instructions. The complimentary oligonucleotide used for RT of CaMKII RNA was 5'-CTCTGGTTCAAAGGCTGTCA-3'. After the RT step, the second PCR oligonucleotide was added: 5'-AGATGCTGACCATCAACCCA-3'. Samples were cycled 40 times through the following amplification series: $30 \mathrm{sec}$ at $94^{\circ} \mathrm{C}, 30 \mathrm{sec}$ at $55^{\circ} \mathrm{C}$, and $60 \mathrm{sec}$ at $72^{\circ} \mathrm{C}$. This protocol produces a $401 \mathrm{bp}$ product from both native and transgenic CaMKII mRNA.

Equal amounts of RT-PCR product (as determined by gel band intensity) were either run on a $1.7 \%$ gel and blotted onto a nylon membrane by capillary transfer with $0.4 \mathrm{M} \mathrm{NaOH}$ or vacuum applied to a nylon membrane. To detect the CaMKII-Asp286 transgene, blots were hybridized overnight at $37^{\circ} \mathrm{C}$ with a ${ }^{32} \mathrm{P}$-labeled oligonucleotide specific to the Asp286 mutation (5'-CTTCAGGCAGTCGACGTCCTCCTGTCTGTG$\left.3^{\prime}\right)$. The hybridization solution contained $50 \%$ formamide, $100 \mathrm{mg} / \mathrm{ml}$ dextran sulfate, $25 \mathrm{~mm}$ HEPES, pH 7.5, $1 \mathrm{~mm}$ EDTA, $0.1 \mathrm{mg} / \mathrm{ml}$ denatured salmon sperm DNA, $0.2 \mathrm{mg} / \mathrm{ml}$ poly-rA, $5 \times$ Denhardt's reagent, $600 \mathrm{~mm}$ $\mathrm{NaCl}$, and $0.1 \%$ SDS. After washing in $0.2 \times \mathrm{SSC}$, the blot was exposed to film and quantified using a phosphorimager. Loading controls were performed by probing the original blot, or a replica blot, with an oligoprobe complementary to wild-type CaMKII (5'-CTTCAGGCAGTCCACGGTCTCCTGTCT-3').

Visible water maze. The water-maze apparatus consisted of a $1.2-\mathrm{m}-$ diameter water-filled pool. In the pool, there was a $10-\mathrm{cm}$-diameter circular platform that lay flush with the surface of the water. Before training, animals were handled in the testing room for $7 \mathrm{~d}$. Training begins $1 \mathrm{~d}$ after the final day of handling. Mice were individually placed onto the raised platform, to which a visible flag had been attached, and allowed to acclimate for $15 \mathrm{sec}$. Mice were then placed in the water and allowed to swim for $15 \mathrm{sec}$, after which time they were guided back to the platform to rest for another $15 \mathrm{sec}$. After acclimatization, mice were placed at a start position along the wall of the tank and given $60 \mathrm{sec}$ to find the visibly flagged platform. If they did not find it in $60 \mathrm{sec}$, they were led back to the platform. Once on the platform, mice were given $30 \mathrm{sec}$ to rest before being returned to their home cage. Two more visibleplatform trials were conducted with the platform, and start locations varied in a pseudorandom manner. Additional days of training (without acclimatization) to a visible platform (three trials per day) may be given to some groups.

Fear-conditioning. Mice were trained in a Plexiglas enclosure containing a wire grid floor, an overhead speaker, and external lighting (Freeze Monitor; San Diego Instruments, San Diego, CA). After a 3 min baseline period, three 20 -sec-long tones $(77 \mathrm{~dB}, 2.8 \mathrm{kHz})$ were played with a $1 \mathrm{~min}$ intertrial interval. A $0.75 \mathrm{~mA}$ foot shock was delivered during the last 1.5 sec of each tone. Twenty-four hours after training, mice were again placed in the original training enclosure for $3 \mathrm{~min}$, and freezing was assessed either by visual scoring or by computer analysis of video frame capture. Two hours later, mice were placed in a new enclosure. After a 3 min baseline exposure, a series of three tones identical to that given in the training session was played, and freezing was scored during the tones.

Field potential electrophysiology. Transverse slices (400 $\mu \mathrm{m}$ thick) of mouse hippocampus were prepared and maintained in an interface slice chamber while being perfused with artificial CSF (aCSF) at $29-31^{\circ} \mathrm{C}$. The aCSF contained the following (in $\mathrm{mM}$ ): $124 \mathrm{NaCl}, 4.4 \mathrm{KCl}, 25$ $\mathrm{NaHCO}_{3}, 1.2 \mathrm{Na}_{2} \mathrm{HPO}_{4}, 1.2 \mathrm{MgSO}_{4}, 10$ glucose, and $2 \mathrm{CaCl}_{2}$. For baseline recording, EPSPs were elicited once every $50 \mathrm{sec}(0.02 \mathrm{~Hz})$ using nichrome wire bipolar stimulation electrodes ( $0.01 \mathrm{msec}$ pulse duration) placed in the stratum radiatum of the CA1 region. The resulting potential was monitored using low-resistance glass microelectrodes (5-15 $\mathrm{M} \Omega$, filled with aCSF) also placed in the stratum radiatum of CA1. In each experiment, the maximal field EPSP amplitude was first determined by gradually increasing the stimulation intensity until the EPSP amplitude reached a saturating level. The stimulation intensity was subsequently decreased so as to evoke a response that was $\sim 50 \%$ of the maximal EPSP amplitude. In all experiments, baseline synaptic transmission was monitored for $20 \mathrm{~min}$ before low-frequency stimulation was delivered. Slices were stimulated at $5 \mathrm{~Hz}$ for $30 \mathrm{sec}$ (150 pulses), and synaptic responses were then monitored at $0.02 \mathrm{~Hz}$ for 1 additional hour.

Gene expression analysis. Gene chip experiments were performed essentially as described previously (Sandberg et al., 2000). The mouse U74 array (GeneChip; Affymetrix, Santa Clara, CA) was used to analyze gene expression patterns in the hippocampus of B13 and B13-DEV mice. Data analysis was performed using GeneChip version 3.1 (Affymetrix) and NFUEGGO 2.1C (Lockhart and Lockhart, San Diego, CA). All samples were scaled to a target intensity of 200, which has been shown to correspond to approximately three to five transcripts per cell.

Samples were obtained from mice expressing high levels of CaMKIIAsp286 (two B13-DEV mice and one B13 mouse) and from CaMKIIAsp286 mice expressing lower levels of their transgene (one B13-DEV mouse and two B13 mice). Two wild-type littermates were included as controls. For the expression of a gene to be considered changed, its level had to be scored as higher or lower in at least four of the six possible comparisons and had to have changed more than twofold.

\section{RESULTS}

\section{Suppression and induction of a tTA-controlled CaMKII-Asp286 transgene}

The mice used in this study carry a mutant $\mathrm{Ca}^{2+}$-independent CaMKII transgene, CaMKII-Asp286, under the control of a tetracycline-responsive promoter (Gossen and Bujard, 1992). This line of mice, designated B13, has been described in a previous article, in which we examined the electrophysiological phenotype in animals that express the transgene throughout development (Mayford et al., 1996). The goal in the present paper was to determine the effect of different levels of transgene expression activated during development or in the adult on both electrophysiology and behavior.

To suppress gene expression during gestation and still allow for rapid induction in the adult, we delivered the tetracycline analog Dox in food at a dose of $40 \mathrm{mg} / \mathrm{kg}$ mouse chow. After Dox withdrawal, the transgene was rapidly activated in neurons throughout the forebrain (Fig. 1A), with maximal expression reached at 2 weeks after Dox withdrawal (Glazewski et al., 2001). However, we found that developmental suppression of the transgene reduced the level of CaMKII-Asp286 that can be induced in the adult. Figure $1 B$ shows the level of transgene expression measured in the hippocampus and striatum from mice in which the transgene was suppressed during gestation and activated only in the adult (B13) and in mice that had the transgene active throughout development (B13-DEV). We examined the impact of these different levels of transgene expression on learning and memory, hippocampal plasticity, and gene expression.

\section{Correlation between behavioral deficits and CaMKII- Asp286 expression levels}

Figure $2 A$ shows a schematic representation of the transgene expression history and behavioral testing points in our first experiment. Animals were allowed to develop with the transgene either on or off. Transgene expression was subsequently sup- 

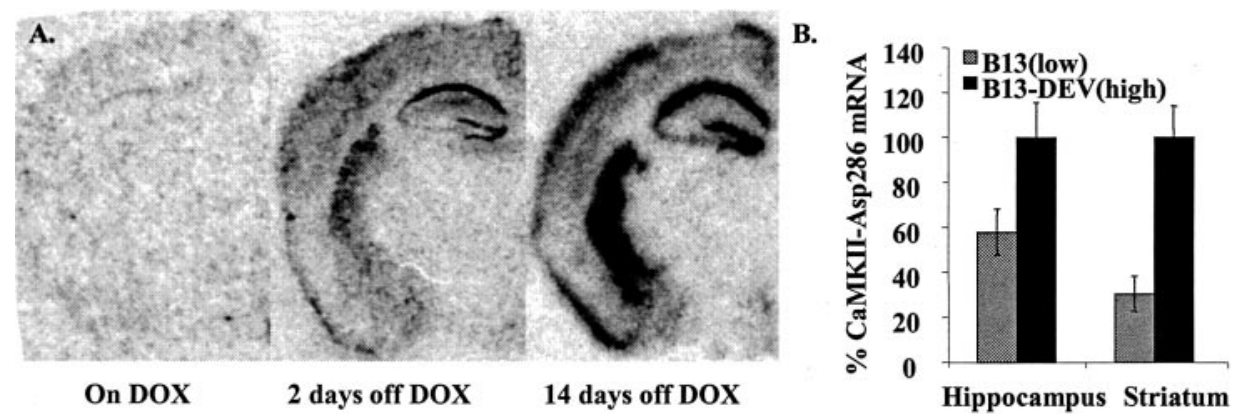

Figure 1. Transgene regulation. A, Expression of transgenic CaMKII-Asp286 mRNA is shown by in situ hybridization in these halfcoronal forebrain sections taken from B13DEV(high) mice. Mice treated with a lowdose doxycycline diet for $>3$ weeks show no expression $(O n D O X)$. Transgene mRNA expression is readily apparent within $2 \mathrm{~d}$ and is present at high levels at $14 \mathrm{~d}$ after mice are switched to a Dox-free diet. Brain slices used in this figure were prepared in parallel, probed with the same radiolabeled oligonucleotide, and exposed to film for the same amount of time. $B$, Mice raised with their transgene suppressed (B13) do not express as much CaMKII-Asp286 mRNA as adults compared with mice that have expressed the transgene throughout development (B13-DEV). The average level of expression in B13-DEV mice has been normalized to 100\%. For hippocampal expression, $p<$ 0.03 ; for striatal expression, $p<0.001$.

A.

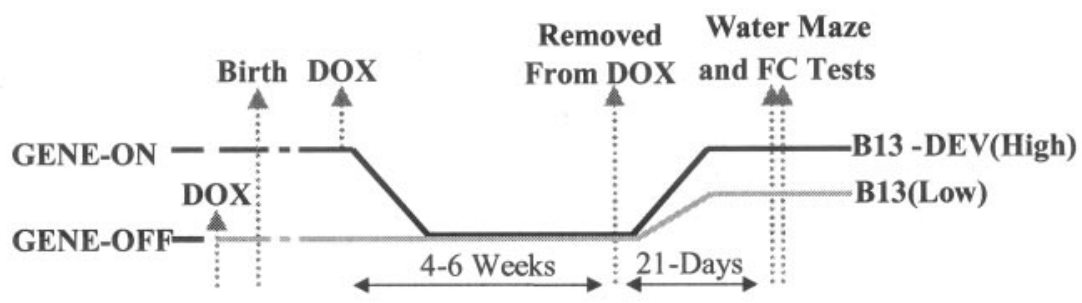

B.

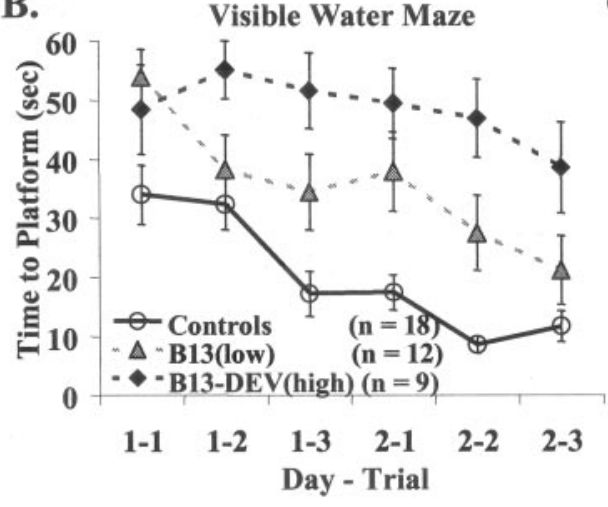

C. Context and Cued Fear Conditioning

100 - Controls

- B13-DEV(high)

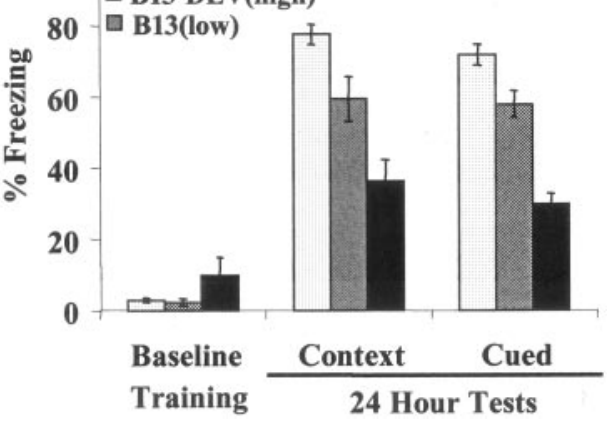

Figure 2. Behavioral effects of CaMKIIAsp286 transgene expression. A, Timeline showing regulation of the CaMKII-Asp286 transgene. B13 mice (gray line) had their transgene off throughout development. In B13DEV mice (black line), the transgene was expressed during development and was first suppressed at 6 weeks of age. At $\sim 11$ weeks of age, both groups of mice had their transgene induced for $21 \mathrm{~d}$ before behavioral testing. $B$, The latency for mice to reach the visible platform is shown as a function of training trial. Across all trials, B13-DEV(high) mice have longer latencies than $\mathrm{B} 13$ (low) mice ( $p<$ 0.02 ), which have longer latencies than control mice $(p<0.001)$. $C$, Degree of freezing in response to training, context, and auditory cues after tone-shock pairings. Despite having similar degrees of baseline freezing $(p>$ 0.05 by ANOVA), B13-DEV(high) mice freeze less to context and cues than do B13(low) mice $(p<0.015)$ and control mice $(p<0.001)$. pressed with Dox in both groups and reactivated before behavioral testing. This produced two groups of mice that differed in level of transgene expression at testing as well as in their developmental exposure to the transgene. We will refer to these groups as B13-DEV(high) and B13(low) to indicate both developmental exposure and level of transgene expression at testing.

Animals were first tested in the visible-platform version of the water maze. As shown in Figure 2B, the two transgenic groups differed from wild-type controls as well as from each other, with the B13-DEV(high) animals being the most severely impaired. A two-way ANOVA with repeated measures showed a significant main effect of group $\left(F_{(2,36)}=26.9 ; p<0.001\right)$ and trial $\left(F_{(5,180)}=8.67 ; p<0.001\right)$, and a post hoc Scheffé test showed that the two transgenic groups differed from each other $(p<$ $0.02)$ and from the wild-type controls $(p<0.001)$. Thus, both groups of mice were impaired on this simple hippocampusindependent task. The impairment on the initial training trial suggests that some sensory, motor, or motivational impairment is responsible for the deficit in these mice. The striatum has been implicated in this simple form of learning, and it is likely that expression of the transgene in this structure contributes to this deficit (Devan et al., 1996).
We subsequently tested performance of the two groups in a simple fear-conditioning task. Again, the mice showed the same general pattern of deficits, with the animals expressing high levels of the transgene showing a more severe impairment (Fig. 2C). A two-way ANOVA showed a significant effect of group $\left(F_{(2,35)}=\right.$ 14.9; $p<0.001$ ) but not of test (cued or context), and a post hoc Scheffé test showed that the B13-Dev(high) group differed significantly from both the wild-type control group and the B13(low) group [B13-DEV(high) vs control, $p<0.001$; B13-DEV(high) vs B13(low), $p<0.02$ ].

The interpretation of these results is complicated by the fact that the two transgenic groups differed not only in the level of transgene expression during behavioral testing but also in exposure to the transgene during development. To distinguish between dose effects and developmental effects, we isolated mRNA from each of the animals that had undergone behavioral testing and determined the level of transgene expression. Figure 3 shows the correlation between levels of transgene expression in individual animals and their performance on the two different behavioral tests. Although the two groups differed on average in transgene expression level (Fig. $1 B$ ), there was significant overlap of individual values. The correlation between the level of transgene 
Figure 3. Correlations between CaMKIIAsp286 gene dose and behavioral performance. $A$, Contextual fear-conditioned freezing $24 \mathrm{hr}$ after training is plotted as a function of CaMKII-Asp286 mRNA levels in the hippocampus. The $R^{2}$ value for all transgenic mice is $0.683(p<0.001)$. $B$, The average latency for mice to reach the visible water-maze platform on day 2 of training is plotted as a function of hippocampal CaMKII-Asp286 mRNA levels. The $R^{2}$ value for all transgenic mice is $0.5270^{\circ}$ $(p<0.001)$. Regardless of transgene exposure during development, animals with a greater transgene dose as adults were more likely to have severe deficits on these tasks. One unit of expression is defined as the amount of mRNA expressed by mice carrying only the tetO-linked CaMKII-Asp286 transgene (no tTA transgene). The control group includes six wild-type mice and three mice carrying only the tetOlinked CaMKII-Asp286 transgene.
A.

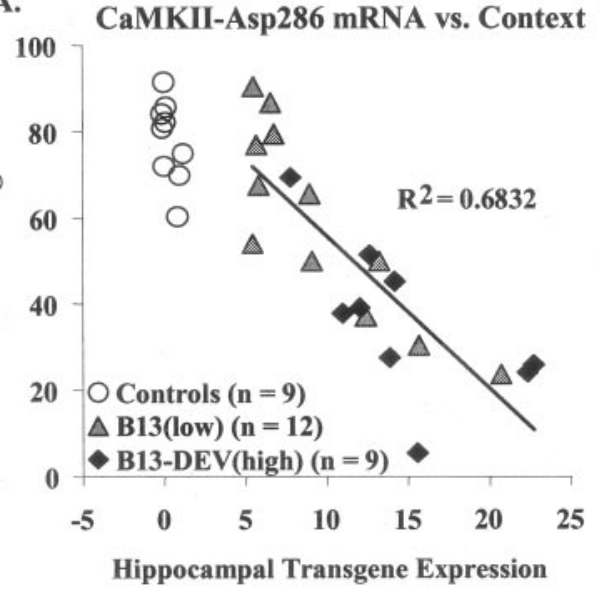

B.

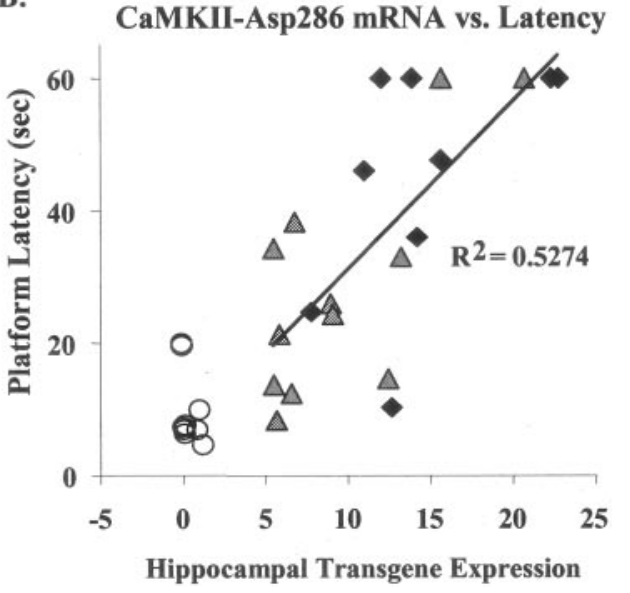

expression in individual animals and the severity of the behavioral deficit was highly significant.

\section{Behavioral deficits are reversible with transgene suppression}

We subsequently examined the reversibility of the behavioral deficits produced in the B13-Dev(high) group of animals. Figure $4 A$ shows the regulation of transgene expression and the timing of behavioral testing. Animals trained and tested with the transgene on showed a severe impairment in contextual fear conditioning (Fig. 4B). After suppression of the transgene, the memory was still significantly impaired, indicating that transgene expression disrupted the encoding of the memory rather than merely affecting performance of the freezing response. Retraining of animals with the transgene suppressed resulted in the formation of wildtype levels of conditioned fear. This demonstrates that although the animals expressed high levels of the transgene during development, the impairment on this task could not be a result of any permanent developmental abnormality. Finally, re-expression of the transgene severely disrupted the freezing of animals conditioned with the transgene suppressed. Similar results were seen in the visible-platform water maze task. As shown in Figure $4 C$, animals trained with the transgene on were strongly impaired at finding the visible platform in the water maze. When the transgene was suppressed, animals rapidly acquired the task to wildtype levels of performance.

\section{Low levels of CaMKII facilitate $5 \mathrm{~Hz}$ LTP induction, but high levels impair 5 Hz LTP induction}

We have previously shown a deficit in Schaffer-collateral LTP induced by low-frequency stimulation in several lines of CaMKII-Asp286 transgenic mice, including the B13 mice used in the present study (Mayford et al., 1995, 1996). The expression of the transgene caused a shift in the response to low-frequency stimulation in the $1-10 \mathrm{~Hz}$ range such that the induction of LTP was reduced and the induction of LTD was enhanced. The transgene dose-dependent effects on behavior led us to re-examine the electrophysiological effects of CaMKII-Asp286 expression. We tested Schaffer-collateral LTP in response to $5 \mathrm{~Hz}$ stimulation in the two populations of CaMKII-expressing mice.

The most striking finding from this experiment (Fig. 5) was that transgenic mice expressing low levels of the CaMKII-Asp286 transgene did not show a shift toward LTD, as had been reported previously, but instead showed an enhanced level of LTP after 5
Hz stimulation $\left(F_{(1,28)}=6.23 ; p<0.05\right)$. Consistent with our previous study, the mice expressing high levels of the transgene had an impairment in LTP induced by the $5 \mathrm{~Hz}$ stimulation protocol $\left(F_{(1,28)}=4.26 ; p<0.05\right)$. Unlike the behavioral results, which demonstrate a quantitative difference in the severity of deficits between the two groups of mice, these LTP results suggest that there is a threshold dose of constitutive CaMKII activity at which there is a qualitative switch from enhanced $5 \mathrm{~Hz}$ LTP to impaired $5 \mathrm{~Hz}$ LTP.

\section{Compensatory changes in gene expression at high levels of CaMKII-Asp286}

Calmodulin-dependent protein kinases have been shown to modulate gene expression (Enslen and Soderling, 1994; Enslen et al., 1994). In a related study, we examined a transgenic line of mice that expressed the CaMKII-Asp286 transgene specifically in the striatum and found a severe disruption in fear-conditioned memory similar to that seen in the present study (K. Hood, unpublished results). DNA microarrays were used in that study to examine potential downstream changes in gene expression and revealed an upregulation in the genes for glutamic acid decarboxylase (GAD65) and tachykinin (Tac), which encode key proteins involved in the generation of the inhibitory neurotransmitters GABA and substance $P$, respectively.

To determine whether mRNA levels of GAD65 and Tac were affected in the CaMKII-Asp286 mice presented here, we performed Northern blots on striatal mRNA obtained from the B13-DEV(high) and B13(low) mutant mice described in Figure 2. Expression of these genes was elevated in the transgenic mice and was significantly correlated with levels of striatal CaMKIIAsp286 mRNA (Fig. 6A,B). The results of an additional Northern blot demonstrate that the increased levels of both GAD65 and Tac are reversible with transgene suppression (Fig. 6C). The reversible nature of this change parallels that of the behavioral phenotype in B13-DEV(high) mice.

These results suggest that in addition to the role of the CaMKII-Asp286 transgene itself, compensatory changes in gene expression may underlie the behavioral phenotypes observed in these animals. We examined gene expression changes in the hippocampus from animals expressing either high or low levels of the CaMKII-Asp286 transgene. We used the mouse U74 GeneChip for these comparisons (Tables 1 and 2). The transcriptional responses in the two groups were qualitatively different. Only two 
A.

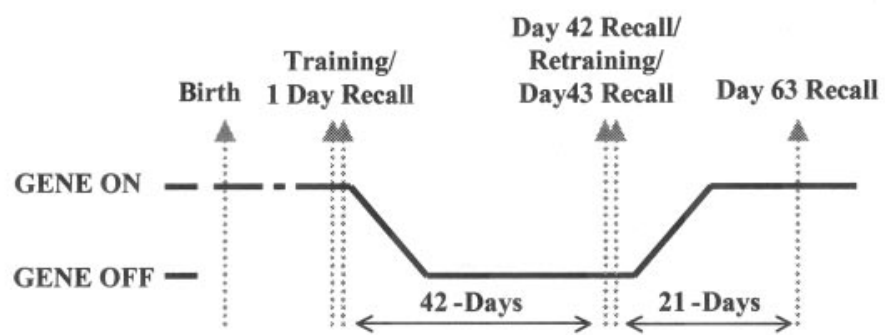

B. Contextual Memory

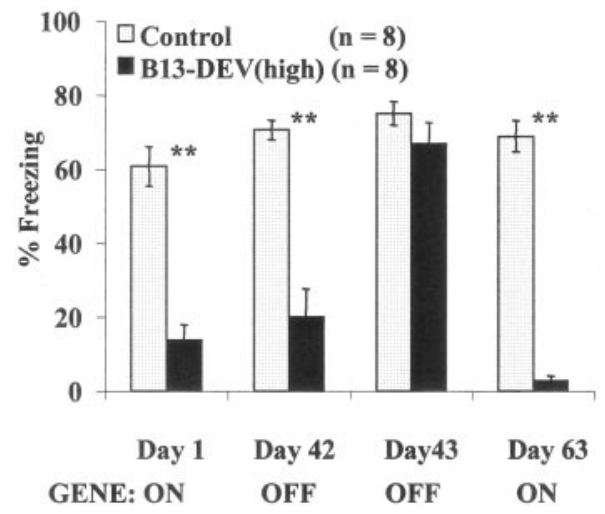

C.

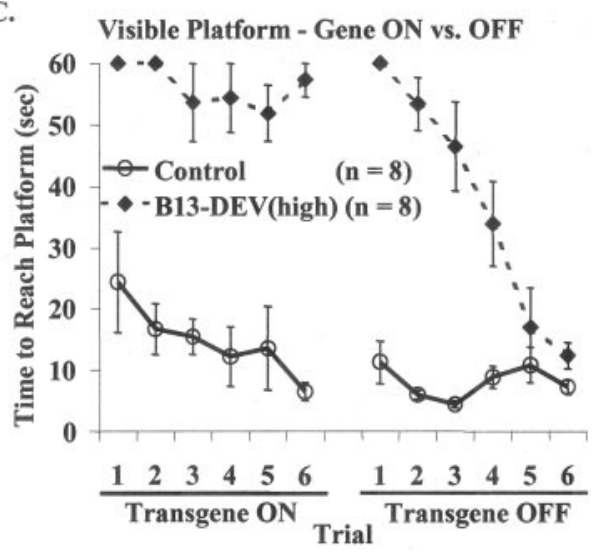

Figure 4. Reversible behavioral deficits in B13-DEV(high) mice. $A$, Timeline showing the CaMKII-Asp286 transgene activation pattern for the experiment shown in $B . B$, Contextual freezing is impaired in B13-DEV(high) mice $24 \mathrm{hr}$ after training with the transgene on and at 6 weeks after transgene suppression (measured during the baseline period immediately before retraining). Twenty-four hours after retraining with the transgene off, B13-DEV (high) mice show normal freezing to context compared with controls. When the transgene is induced after normal learning, B13-DEV (high) mice have a complete lack of freezing to the context learned previously. ${ }^{* *} p<0.001$. $C$, B13-DEV(high) mice fail to locate a visible platform in the water maze, whereas controls acquire this task readily. After transgene suppression, B13-DEV(high) mice learn to locate the visible platform (performance on last two trials, wild-type vs B13 mice; $p=0.14$; NS). genes showed expression changes in both the high- and lowexpressing groups and could therefore be directly linked to the levels of CaMKII-Asp286 transgene expression (spi2, B-cellspecific protein). Many of the genes that are upregulated specifically in the hippocampus of animals expressing high levels of CaMKII-Asp286 are also known to be upregulated in response to synaptic activity and LTP-inducing stimuli [transforming growth factor- $\beta$-inducible early growth response, zif/268, Jun-B, pip92, neuropeptide Y (NPY), inhibin $\beta$-A subunit (IHBA), and regulator of G-protein signaling 2] (Inokuchi et al., 1996; Ingi et al., 1998; Marty, 2000). Others can be characterized as genes whose expression levels are altered by injurious or inflammatory stimuli (GFAP, A11, and IHBA) (Lai et al., 1996; Tretter et al., 1996). The induction of NPY suggests that as CaMKII levels increase, the increased excitatory activity triggers a compensatory increase in this inhibitory transmitter. NPY is known to reduce presynaptic glutamate release and impair the induction of LTP (Qian et al., 1997; Whittaker et al., 1999). The induction of genes associated with inflammatory stimuli suggests that some excitotoxic damage may occur at high levels of CaMKII.

\section{DISCUSSION}

Genetically modified mice have been used extensively to address the molecular mechanisms of complex neurobiological phenomena such as synaptic plasticity, learning, and memory. One of the difficulties of this approach is dissociating primary effects on learning mechanisms from potential secondary effects that a genetic modification may have on neuronal development or on compensatory changes in the expression of other genes (Mayford and Kandel, 1999). We used Tet-regulated transgene expression in combination with behavioral, electrophysiological, and gene expression profiling using DNA chips to address the role of CaMKII signaling in LTP and behavior.

Using the Tet system, we have shown that transgene expression
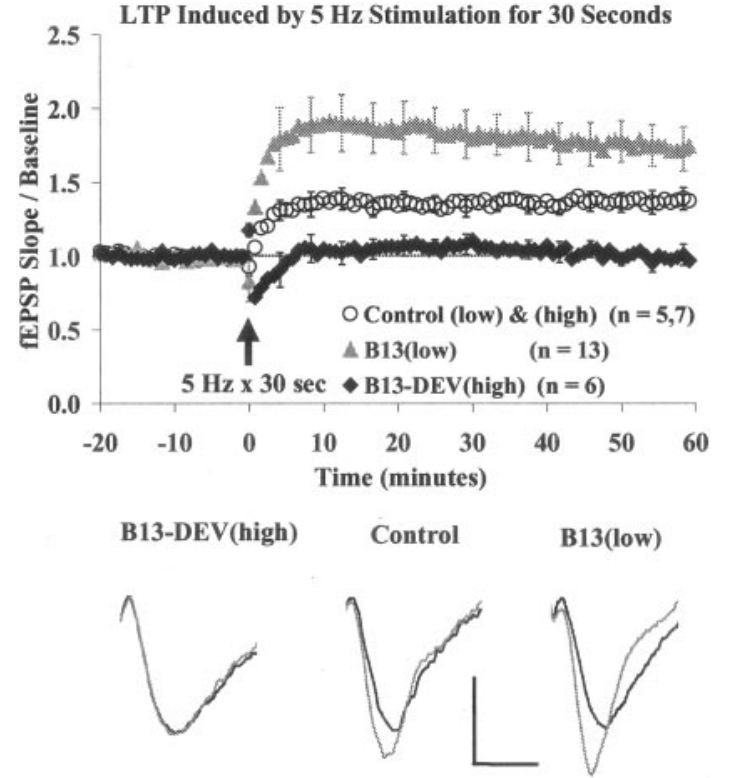

Figure 5. CaMKII-Asp286 expression alters theta-frequency LTP. Hippocampal LTP induced by $5 \mathrm{~Hz}$ stimulation in B13(low) and B13DEV(high) groups during CaMKII-Asp286 expression is shown. Hippocampal slices from B13(low) and B13-DEV(high) groups were stimulated at $0.02 \mathrm{~Hz}$ while EPSPs were recorded from CA1 dendritic fields. After $20 \mathrm{~min}$ of baseline, slices were stimulated at $5 \mathrm{~Hz}$ for $30 \mathrm{sec}$, followed by $1 \mathrm{hr}$ of $0.02 \mathrm{~Hz}$ recording. Note how B13(low) and B13$\mathrm{DEV}$ (high) mutants have opposing responses to $5 \mathrm{~Hz}$ stimulation. B13DEV(high) mutants have an LTP deficit, whereas B13(low) mutants trend toward enhanced LTP at this stimulation frequency. Representative EPSPs for each group of animals tested are shown before and after the 5 $\mathrm{Hz}$ stimulation. Calibration, $10 \mathrm{msec}, 2 \mathrm{mV}$. 

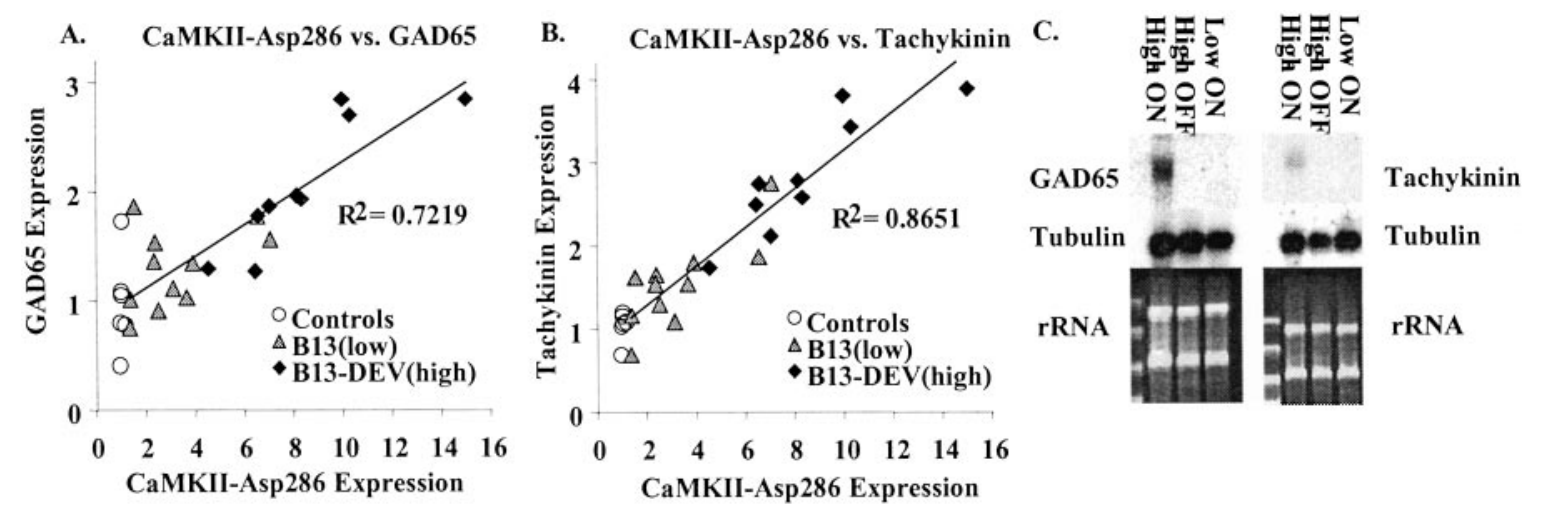

Figure 6. Striatal GAD65 and tachykinin expression correlates with CaMKII-Asp286 expression. A, Striatal expression of CaMKII-Asp286 and GAD65 co-vary, with an $R^{2}$ value for all transgenic mice of $0.722(p<0.001)$. $B$, Striatal expression of CaMKII-Asp286 and Tac co-vary, with an $R^{2}$ value for all transgenic mice of $0.865(p<0.001)$. Expression levels were assayed by Northern blot of total striatal RNA and normalized for levels of tubulin mRNA. One unit of expression is defined as the amount of mRNA expressed by mice carrying only the tetO-linked CaMKII-Asp286 transgene (no tTA transgene). The control group includes four wild-type mice and two mice carrying only the tetO-linked CaMKII-Asp286 transgene. $C$, Northern blots for GAD65 and Tac mRNA. Whole-forebrain RNA from B13-DEV(high) mutant mice with their transgene induced (High ON) and suppressed (High $O F F$ ) as well as from B13(low) mutants with their transgene induced (Low ON) is probed for GAD65. At this exposure, significant expression is seen only in the B13-DEV(high) mice tested with their transgene expressed (High ON).

can be effectively suppressed during development with low levels of Dox that allow relatively rapid transgene induction in adult animals. A surprising finding was that suppression of transgene expression during development led to a reduction in the adult levels of gene expression that could be obtained. Although this could result from residual Dox in those animals that were exposed to the drug during gestation, we think it is more likely a result of alterations in genomic DNA in the neighborhood of the tetOlinked transgene. We favor this view because even prolonged withdrawal from Dox does not lead to consistently high levels of expression in these mice, and in a second line of tetO-linked CaMKII-Asp286 transgenic mice, we found that developmental suppression of transgene expression completely eliminated the ability to induce the transgene in adult animals (Hood, unpublished results). This may result from changes in chromatin structure or DNA methylation at the inactive transgene locus (Pikaart et al., 1998) and points out the need to consider expression history when using inducible transgenic systems.

Previous studies using pharmacological inhibitors and knockout mice support the view that CaMKII activation and autophosphorylation at Thr286 is required for the induction of LTP (Malenka et al., 1989; Malinow et al., 1989; Silva et al., 1992a; Giese et al., 1998). Studies using transfection in hippocampal slice cultures or injection of monomeric forms of CaMKII suggest that activation of the kinase is sufficient to induce LTP (Pettit et al., 1994; Lledo et al., 1995), possibly by acting on AMPA-type glutamate receptors (Hayashi et al., 2000). However, in previous studies of CaMKII-Asp286 transgenic mice, we failed to see transgene-induced potentiation or LTP occlusion, as would be expected if CaMKII activation were sufficient to produce LTP (Mayford et al., 1995, 1996). Instead, we found a shift in response to low-frequency stimulation in the $1-10 \mathrm{~Hz}$ range such that the threshold frequency necessary to induce LTP was increased. We now find that the electrophysiological phenotype is sensitive to the level of transgene expression such that at low levels of CaMKII-Asp286 expression, LTP induction by $5 \mathrm{~Hz}$ stimulation is facilitated, whereas at high levels of CaMKII-Asp286, LTP induction by $5 \mathrm{~Hz}$ stimulation is impaired. High levels of CaMKII-Asp286 expression also lead to compensatory changes in expression of other genes in the hippocampus. One of these compensatory changes is an upregulation of NPY. NPY is known to act presynaptically to oppose glutamate release and the induction of LTP (Qian et al., 1997; Whittaker et al., 1999).

Together, these results suggest that the primary effect of CaMKII-Asp286 expression is to facilitate the induction of LTP, but that at high levels of expression, compensatory changes mask that effect. This is consistent with the view that CaMKII activation is necessary for LTP induction. Lisman and Zhabotinsky (2001) proposed a model, based on the known biochemistry of CaMKII and of associated protein phosphatases, in which the CaMKII holoenzyme has two stable states, either highly autophosphorylated (active) or largely dephosphorylated (inactive). In this model, inclusion of an activated mutant subunit that could not be dephosphorylated should produce a primed state in which the switch to fully phosphorylated holoenzyme would occur at lower calcium levels. If this were the case, the smaller calcium influx produced at lower frequencies of stimulation would be expected to produce a greater amount of potentiation in the CaMKII-Asp286 mutant, as was seen in this study.

Activation of CaMKII to low levels produces deficits in visibleplatform water maze performance only in adult animals. This is not a hippocampus-dependent task and is most likely mediated by physiological effects in other brain regions, such as the striatum (Devan et al., 1999). However, it is worth noting that although this low level of CaMKII activation facilitates the induction of LTP, at least in one pathway in the hippocampus, the animals show impaired performance on this task. At high levels of transgene expression, severe deficits occur in visible-platform water maze and cued and contextual fear conditioning. These deficits are fully reversible, and the severity of the deficit is correlated with the level of transgene expression. Moreover, the behavioral deficits are paralleled by changes in inhibitory transmitter systems in both the striatum and the hippocampus.

These results are consistent with the idea that the primary effect of CaMKII activation is excitatory, possibly by facilitating the induction of LTP. The shift in LTP threshold at low levels of transgene expression results in mild behavioral impairments that may be attributable to inappropriate synaptic weight changes in response to a given environmental stimulus. At high levels of transgene expression, compensatory upregulation of inhibitory 
Table 1. Changes in hippocampal gene expression between mice expressing high levels of CaMKII-Asp286

\begin{tabular}{|c|c|c|}
\hline $\begin{array}{l}\text { Accession } \\
\text { number }\end{array}$ & Gene name & $\begin{array}{l}\text { Fold } \\
\text { change }\end{array}$ \\
\hline M64086.1 & $\begin{array}{l}\text { spi2 proteinase inhibitor } \\
\text { (spi2/eb4) }\end{array}$ & 56.7 \\
\hline NM_009112.1 & $\begin{array}{l}\text { Calcium-binding protein } \\
\text { A11, calgizzarin }\end{array}$ & 15.6 \\
\hline M61181.1 & BDNF & 11.2 \\
\hline AA 656550 & Unknown & 10.6 \\
\hline AB032087.1 & $\begin{array}{l}\text { RM1 (induced during hippo- } \\
\text { campal LTP) }\end{array}$ & 7.9 \\
\hline NM_008981.1 & $\begin{array}{l}\text { Protein tyrosine phosphatase } \\
\text { receptor type } G\end{array}$ & 7.4 \\
\hline NM_012488.1 & $\alpha_{2}$-Macroglobulin & 7.4 \\
\hline L26490.1 & pip92 & 5.5 \\
\hline X69619.1 & Inhibin $\beta$-A subunit & 5.0 \\
\hline NM_013692.1 & $\begin{array}{l}\text { Transforming growth factor } \\
\beta \text {-inducible early growth } \\
\text { response }\end{array}$ & 5.0 \\
\hline AF273768.1 & $\begin{array}{l}\text { Preproneuropeptide Y } \\
\text { (NPY) }\end{array}$ & 4.9 \\
\hline AJ222814.1 & B-cell-specific protein & 4.7 \\
\hline K01347.1 & GFAP & 3.8 \\
\hline NM_009061.1 & $\begin{array}{l}\text { Regulator of G-protein } \\
\text { signaling } 2\end{array}$ & 2.9 \\
\hline M22326.1 & zif $/ 268$ & 2.9 \\
\hline AI839690 & Unknown & 2.5 \\
\hline X66295.1 & C1q C-chain & 2.3 \\
\hline NM_008416.1 & Jun-B & 2.1 \\
\hline AF064635 & Unknown & 2.1 \\
\hline X92439.1 & Collagen type IV, $\alpha_{1}$ chain & 2.0 \\
\hline U49251 & T-Brain-1 & 2.0 \\
\hline J00413.1 & $\beta$-Globin & -2.0 \\
\hline V00714.1 & $\alpha$-Globin & -2.1 \\
\hline NM_008731.1 & Neuropeptide Y receptor-Y2 & -2.5 \\
\hline AA 600542 & Unknown & -2.6 \\
\hline
\end{tabular}

Hippocampal RNA was screened on Affymetrix gene chips (Mouse U74). Compensatory changes in gene expression in three mice with high levels of CaMKII-Asp286 (two mice with the transgene on during development, one mouse with the transgene off during development) compared with two wild-type mice. Genes that were scored as changed over twofold in at least four of the six possible comparisons between transgenic and control mice are shown.

neurotransmitter systems acts to oppose increased excitation and prevent excessive neuronal activity and seizure, at least in the hippocampus. In the striatum, in which the medium spiny neurons are GABAergic projection neurons, the changes in gene expression may represent an increase in striatal output resulting from facilitated corticostriatal transmission (Hood, unpublished results). The severe behavioral impairments could result from these secondary changes in transmission.

How do these results reflect the role of CaMKII activation in response to natural stimuli? Behaviorally induced changes in CaMKII activity have not been studied extensively; however, after LTP induction, autophosphorylated CaMKII is elevated for at least 1 hr (Fukunaga et al., 1993; Ouyang et al., 1997). The present study uses prolonged expression of a constitutively active mutant form of CaMKII and may be similar to the type of kinase activation that occurs with prolonged or repeated neuronal activity. The results suggest that at a high enough level of CaMKII
Table 2. Changes in hippocampal gene expression between mice expressing low levels of CaMKII-Asp286

\begin{tabular}{llc}
$\begin{array}{l}\text { Accession } \\
\text { number }\end{array}$ & Gene name & $\begin{array}{c}\text { Fold } \\
\text { change }\end{array}$ \\
\hline NM_013697.1 & Transthyretin & 33.1 \\
M64086.1 & spi2 proteinase inhibitor (spi2/eb4) & 24.9 \\
AB005141.1 & Klotho & 23.8 \\
U52925 & Coagulation factor V & 9.6 \\
AI845874 & Unknown & 6.3 \\
AI847646 & Unknown & 5.6 \\
NM_008489.1 & Lipopolysaccharide-binding protein & 4.1 \\
L14811.1 & Prolactin receptor & 3.7 \\
NM_015744.1 & Ectonucleotide pyrophosphatase/ & 2.3 \\
& phosphodiesterase 2 & \\
AJ222814.1 & B-cell-specific protein & 2.1 \\
AW049647 & Unknown & 2.1 \\
M13227.1 & Enkephalin & -2.4 \\
X13986.1 & Minopontin & -5.7
\end{tabular}

Hippocampal RNA was screened on Affymetrix gene chips (Mouse U74). Compensatory changes in gene expression in three mice with low levels of CaMKII-Asp286 (one mouse with the transgene on during development, two mice with the transgene off during development) compared with the same two wild-type mice used for Table 1. Genes that were scored as changed over twofold in at least four of the six possible comparisons between transgenic and control mice are shown.

activity, a set of compensatory transcriptional changes occurs that may act to oppose the effect of elevated kinase activity. Some of these transcriptional changes may be triggered in a direct cellautonomous manner by phosphorylation of CaMKII substrates. At a molecular level, the response may be triggered at levels of activated kinase that allow significant phosphorylation of lowaffinity substrates or that alter the subcellular distribution of the kinase. In addition, some of the compensatory changes are likely to be non-cell autonomous but reflect a system-wide response to increased excitatory activity associated with CaMKII activation. For example, the increase in NPY in the hippocampus is probably a non-cell autonomous response, because NPY is expressed in interneurons that do not express the CaMKII-Asp286 transgene.

These results highlight some of the difficulties in studying genetically modified mice in general and in a highly adaptive system such as the brain in particular. The introduction of a single genetic alteration, even in an inducible manner, can have significant downstream consequences that can complicate interpretation. The advent of GeneChip technology coupled with the sequencing of the mouse genome should make it theoretically possible to detect many of the compensatory changes in gene expression, reflected at the RNA level, that occur in a given mutant animal. This level of analysis, coupled with regulated genetic systems such as Tet and more anatomically restricted promoters, should enhance our ability to understand how single gene changes exert their effects on complex neurobiological processes.

\section{REFERENCES}

Bach ME, Hawkins RD, Osman M, Kandel ER, Mayford M (1995) Impairment of spatial but not contextual memory in CaMKII mutant mice with a selective loss of hippocampal LTP in the range of the theta frequency. Cell 81:905-915.

Devan BD, Goad EH, Petri HL (1996) Dissociation of hippocampal and striatal contributions to spatial navigation in the water maze. Neurobiol Learn Mem 66:305-323.

Devan BD, McDonald RJ, White NM (1999) Effects of medial and lateral caudate-putamen lesions on place- and cue-guided behaviors in the water maze: relation to thigmotaxis. Behav Brain Res 100:5-14. 
Enslen H, Soderling TR (1994) Roles of calmodulin-dependent protein kinases and phosphatase in calcium-dependent transcription of immediate early genes. J Biol Chem 269:20872-20877.

Enslen H, Sun P, Brickey D, Soderling SH, Klamo E, Soderling TR (1994) Characterization of $\mathrm{Ca}^{2+} /$ calmodulin-dependent protein kinase. IV. Role in transcriptional regulation. $J$ Biol Chem 269:15520-15527.

Fukunaga K, Stoppini L, Miyamoto E, Muller D (1993) Long-term potentiation is associated with an increased activity of $\mathrm{Ca}^{2+}$ / calmodulin-dependent protein kinase II. J Biol Chem 268:7863-7867.

Giese KP, Fedorov NB, Filipkowski RK, Silva AJ (1998) Autophosphorylation at thr286 of the alpha calcium-calmodulin kinase II in LTP and learning. Science 279:870-873.

Glazewski S, Bejar R, Mayford M, Fox K (2001) The effect of autonomous alpha-CaMKII expression on sensory responses and experiencedependent plasticity in mouse barrel cortex. Neuropharmacology 41:771-778.

Gossen M, Bujard H (1992) Tight control of gene expression in mammalian cells by tetracycline-responsive promoters. Proc Natl Acad Sci USA 89:5547-5551.

Hayashi Y, Shi SH, Esteban JA, Piccini A, Poncer JC, Malinow R (2000) Driving AMPA receptors into synapses by LTP and CaM KII: requirement for GluR1 and PDZ domain interaction. Science 287:2262-2267.

Ingi T, Krumins AM, Chidiac P, Brothers GM, Chung S, Snow BE, Barnes CA, Lanahan AA, Siderovski DP, Ross EM, Gilman AG, Worley PF (1998) Dynamic regulation of RGS2 suggests a novel mechanism in G-protein signaling and neuronal plasticity. J Neurosci 18:7178-7188.

Inokuchi K, Kato A, Hiraia K, Hishinuma F, Inoue M, Ozawa F (1996) Increase in activin beta A mRNA in rat hippocampus during long-term potentiation. FEBS Lett 382:48-52.

Lai M, Sirimanne E, Williams CE, Gluckman PD (1996) Sequential patterns of inhibin subunit gene expression following hypoxic-ischemic injury in the rat brain. Neuroscience 70:1013-1024.

Lisman J, Malenka RC, Nicoll RA, Malinow R (1997) Learning mechanisms: the case for CaM-KII. Science 276:2001-2002.

Lisman JE, Zhabotinsky AM (2001) A model of synaptic memory: a CaMKII/PP1 switch that potentiates transmission by organizing an AMPA receptor anchoring assembly. Neuron 31:191-201.

Lledo PM, Hjelmstad GO, Mukherji S, Soderling TR, Malenka RC, Nicoll RA (1995) Calcium/calmodulin-dependent kinase II and longterm potentiation enhance synaptic transmission by the same mechanism. Proc Natl Acad Sci USA 92:11175-11179.

Malenka RC, Kauer JA, Perkel DJ, Mauk MD, Kelly PT, Nicoll RA, Waxham MN (1989) An essential role for postsynaptic calmodulin and protein kinase activity in long-term potentiation. Nature 340:554-557.

Malinow R, Schulman H, Tsien RW (1989) Inhibition of postsynaptic PKC or CaMKII blocks induction but not expression of LTP. Science 245:862-866.

Marty S (2000) Differences in the regulation of neuropeptide Y, somatostatin and parvalbumin levels in hippocampal interneurons by neuronal activity and BDNF. Prog Brain Res 128:193-202.

Mayford M, Kandel ER (1999) Genetic approaches to memory storage. Trends Genet 15:463-470.

Mayford M, Wang J, Kandel ER, O’Dell TJ (1995) CaMKII regulates the frequency-response function of hippocampal synapses for the production of both LTD and LTP. Cell 81:891-904.

Mayford M, Bach ME, Huang YY, Wang L, Hawkins RD, Kandel ER (1996) Control of memory formation through regulated expression of a CaMKII transgene. Science 274:1678-1683.

Ouyang Y, Kantor D, Harris KM, Schuman EM, Kennedy MB (1997) Visualization of the distribution of autophosphorylated calcium/ calmodulin-dependent protein kinase II after tetanic stimulation in the CA1 area of the hippocampus. J Neurosci 17:5416-5427.

Pettit DL, Perlman S, Malinow R (1994) Potentiated transmission and prevention of further LTP by increased CaMKII activity in postsynaptic hippocampal slice neurons. Science 266:1881-1885.

Pikaart MJ, Recillas-Targa F, Felsenfeld G (1998) Loss of transcriptional activity of a transgene is accompanied by DNA methylation and histone deacetylation and is prevented by insulators. Genes Dev 12:2852-2862.

Qian J, Colmers WF, Saggau P (1997) Inhibition of synaptic transmission by neuropeptide $\mathrm{Y}$ in rat hippocampal area CA1: modulation of presynaptic $\mathrm{Ca}^{2+}$ entry. J Neurosci 17:8169-8177.

Sandberg R, Yasuda R, Pankratz DG, Carter TA, Del Rio JA, Wodicka L, Mayford M, Lockhart DJ, Barlow C (2000) Regional and strainspecific gene expression mapping in the adult mouse brain. Proc Natl Acad Sci USA 97:11038-11043.

Silva AJ, Stevens CF, Tonegawa S, Wang Y (1992a) Deficient hippocampal long-term potentiation in alpha-calcium-calmodulin kinase II mutant mice. Science 257:201-206.

Silva AJ, Paylor R, Wehner JM, Tonegawa S (1992b) Impaired spatial learning in alpha-calcium-calmodulin kinase II mutant mice. Science 257:206-211.

Tretter YP, Munz B, Hubner G, ten Bruggencate G, Werner S, Alzheimer C (1996) Strong induction of activin expression after hippocampal lesion. NeuroReport 7:1819-1823.

Whittaker E, Vereker E, Lynch MA (1999) Neuropeptide Y inhibits glutamate release and long-term potentiation in rat dentate gyrus. Brain Res 827:229-233. 